\title{
PROTEINI-AINEIDEN VAIHTELUSTA VAARAMORENILLA JA MUTASUOTURPEELLA KASVANEESSA VILJASSA
}

\author{
LaUri SALOHEIMo \\ Karjalan suoviljelyskoeasema, Tohmajärvi.
}

Saapunut 1.6. 1949 .

Kasvualustan vaikutus viljelyskasvien kemialliseen kokoomukseen on eräissä suhteissa ollut tunnettu jo pidempien aikojen kuluessa. Niinpä suoviljelysten tuottamaa heinää on yleisesti pidetty kivennäisainemäärältään heikompilaatuisena kuin savi- ja hietamaitten heinää. Näin on asianlaita ainakin niillä suoviljelyksillä, missä ei ole käytetty maanparannusaineita eikä kali-fosfaattilannoitusta. Vastaavanlaista tietoa on jo vuosikymmenien aikana ollut oluttehtailijoilla, jotka eivät ole halunneet käyttää suolla kasvanutta ohraa tehtaissaan, koska panimo-ohran proteiniprosentin tulee. olla 9-10, mutta ei enempää eikä vähempää.

Kivennäismaat ja suot poikkeavat toisistaan mm. maaperän luonnostaan sisältämään typpimäärään nähden. VALMARIn (4) mukaan ovat Suomen maalajeista paitsi kivennäismaat myös rahkaturve typpiköyhää (savetussa rahkaturpeessa $7.6 \%$ ja rahkaturpeessa $12.1 \%$ typpeä $20 \mathrm{sm}$ syvässä kerroksessa). Sen sijaan sekaturpeen hehtaaria kohti sisältämä typpimäärä on VALMARIn mukaan noin 2 kertaa ja mutasuoturpeen $3 \frac{1}{2}$ kertaa niin suuri kuin kivennäismaan (hiekka- ja hietamaa $1.52 \%$, savimaa $1.91 \%$, mutasuoturve $24.6 \%$ ja sekaturve $18.5 \%$ typpeä 20 sm syvässä maakerroksessa).

Kun mutasuoviljelyksen kasvit joutuvat levittämään juuristonsa typpirikkaaseen maaperään, on otaksuttavaa, että ne täällä käyttäisivät ravintonaan suhteellisesti enemmän typpeä kuin kivennäismaalla. Tämän voi päätellä mm. suolla kasvavan viljan lehtien tummanvihreästä väristä.

VALLE (3) on kiinnittänyt huomiota kauran sisältämiin eri suuriin raakaproteinimääriin. Hänen mukaansa tämän kasvin raakaproteinisisältö nousee huomattavasti kauran kanssa viljeltävän herneen tai virnan vaikutuksesta. Herne ja virna kokoovat ilmakehän typpeä ja luovuttavat sitä seassa kasvaneelle kauralle siinä määrin, että typellisten aineiden suhteellinen määrä kauran jyvissä on noussut jossain tapauksessa jopa neljänneksellä. 
Taulukko 1. Eri maalajien kasvinravintoaineiden suhteet Suoviljelysyhidstyksen Karjalan koeasemalla Kivisen mukaan.

Tabelle 1. Die Verhältnisse der Pflanzennährstoffe verschiedener Bodenarten auf der karelischen Versuchsstation des Moorkulturvereins, nach KIVINEN.

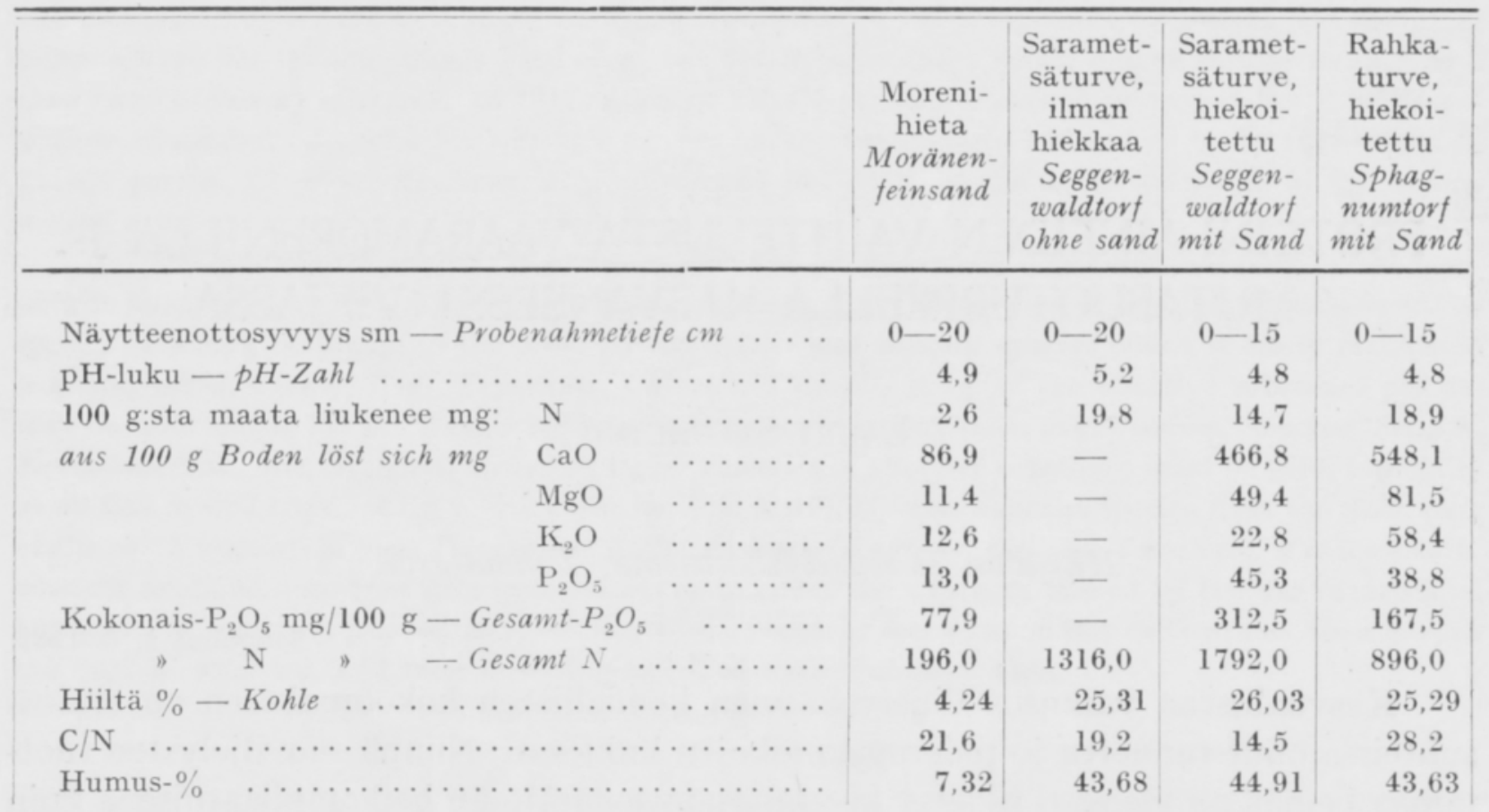

RindelL (2) on meillä ensimmäisenä kiinnittänyt huomiota, miten mutaturvesuon luonnonvaraiset, runsaat typpimäärät vaikuttavat suoviljelyksen kasveihin. Hänen tutkimustensa mukaan kasvit kokoovat suolla itseensä suhteellisesti enemmän typellisiä aineita kuin kivennäismaalla. Poikkeuksen on tässä suhteessa tehnyt vain timotei.

Suoviljelysyhdistyksen Karjalan koeasemalla Tohmajärvellä on eräinä vuosina tarkkailtu vaaralla ja suolla kasvaneen viljan jyvien proteinipitoisuutta. Kun näitten eroavaisuudet perustuvat ennen muuta maalajien eri suuriin typpimääriin, tarkastamme ensin eräitä sanotun koeaseman viljelysmaitten maa-analyysituloksia. Analyysit on suorittanut professori Kivinen v. 1935 (5, p. 12-13). Tulokset esitetään taulukossa 1. Niiden selostuksessa KIVInEN mainitsee, että Tohmajärven koeaseman turvemaissa on runsaasti liukenevaa typpeä. Kun taulukossa esitettyjä lukuja verrataan VALMARIn lukuihin, havaitaan, että koeaseman sarametsäturpeen kokonaistyppimäärä on vastannut vain tavallista sekaturpeen typpimäärää ja ollut jopa tätäkin pienempi. Koeaseman rahkaturve, joka on papillosum-turvetta, on sitä vastoin ollut jonkin verran tämän turvelajin keskimäärää typpirikkaampaa. Kun hiilen suhde typpeen (C/N) on KIVIsen (1, p. 128) tutkimusten mukaan vaihdellut maamme turvelajeissa 37,7:stä 14,9:ään, on se koeaseman hiekoitetulla mutasuoviljelyksellä ollut 14,5. Toteamme, että tämä suhde on koeasemalla ollut viljelyskasveille edullinen. 
Taulukko 2. Kevätvehnälajikkeitten sadot ja sadon laatu vaaramoreenilla ja mutaturvesuolla v. 1943.

Tabelle 2. Evträge und Evtragsbeschaffenheit von Sommerweizenzuchtsorten auf Vaara-Moräne und Niederungsmoor im J. 1943.

\begin{tabular}{|c|c|c|c|c|c|c|c|c|}
\hline \multirow{3}{*}{$\begin{array}{l}\text { Lajike } \\
\text { Zuchtsorte }\end{array}$} & \multicolumn{4}{|c|}{$\begin{array}{l}\text { Vaaramorenilla } \\
\text { Vaara-Moräne }\end{array}$} & \multicolumn{4}{|c|}{$\begin{array}{l}\text { Mutaturvesuolla } \\
\text { Niederungsmoor }\end{array}$} \\
\hline & \multicolumn{2}{|c|}{$\begin{array}{l}\text { Sato } \mathrm{kg} / \mathrm{ha} \\
\text { Evtrag } \mathrm{kg} / \mathrm{ha}\end{array}$} & \multicolumn{2}{|c|}{$\begin{array}{l}\text { Jyväsadon } \\
\text { Kornertrag }\end{array}$} & \multicolumn{2}{|c|}{$\begin{array}{l}\text { Sato } \mathrm{kg} / \mathrm{ha} \\
\text { Evtrag } \mathrm{kg} / \mathrm{ha}\end{array}$} & \multicolumn{2}{|c|}{$\begin{array}{l}\text { Jyväsadon } \\
\text { Kornertrag }\end{array}$} \\
\hline & $\begin{array}{l}\text { jyviä } \\
\text { Körner }\end{array}$ & $\begin{array}{l}\text { olkia } \\
\text { Stroh }\end{array}$ & $\begin{array}{l}\text { raaka- } \\
\text { prot- } \% \\
\text { Rohpro- } \\
\text { tein-\% }\end{array}$ & $\begin{array}{r}\text { rouheluku } \\
\text { Schrotzahl }\end{array}$ & $\begin{array}{l}\text { jyviä } \\
\text { Körner }\end{array}$ & $\begin{array}{l}\text { olkia } \\
\text { Stroh }\end{array}$ & $\begin{array}{l}\text { raaka- } \\
\text { prot- } \% \\
\text { Rohpro- } \\
\text { tein-\% }\end{array}$ & $\begin{array}{l}\text { rouheluku } \\
\text { Schrotzahl }\end{array}$ \\
\hline Timantti - & & & & & & & & \\
\hline Diamant.. & $2200 \pm 100$ & 4620 & 13,04 & 44 & $1290 \pm 60$ & 6160 & 18,06 & 27 \\
\hline Hopea .... & $2010 \pm 100$ & 4590 & 13,92 & 35 & $1790 \pm 50$ & 5960 & 18,21 & 33 \\
\hline Tammi .... & $1980 \pm 120$ & 4770 & 13,83 & 65 & $1540 \pm 70$ & 5430 & 17,99 & 41 \\
\hline Sopu ..... & $2070 \pm 70$ & 5180 & 13,83 & 42 & $1430 \pm 50$ & 6170 & 17,45 & 31 \\
\hline Pika II .... & $1820 \pm 70$ & 4680 & 14,16 & 40 & $1380 \pm 70$ & 6240 & 18,67 & 27 \\
\hline
\end{tabular}

\section{Suoviljelysyhdistyksen Karjalan koeaseman vertailevat tutkimukset vilian proteinimääristä.}

Koeasemalla kiinnitettiin v. 1943 huomio suolla kasvaneen viljan laatuun siten, että joukko viljanäytteitä lähetettiin professori VALLEn ehdotuksesta valtion viljantutkimuslaitokselle tutkimusta varten. Kevätvehnälajikenäytteistä suoritti mainittu laitos mm. proteinimääräyksen. Kun osa vehnistä oli kasvanut vaaralla ja osa mutasuolla, tuli eri maalajien laatueroitus siten näkyviin. Koekasvit olivat saaneet seuraavanlaatuisen lannoituksen: vaaramaankokeen esikasvi ruis sai karjan-

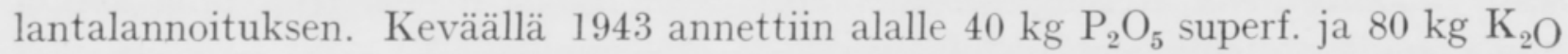
$40 \%$ kalisuolana ha:lle. Yhtä suuren lannoituksen sai myös mutasuon lajikekoe. V. 1940 syksyllä oli jälkimmäinen koeala saanut $200 \mathrm{~m}^{3}$ hiekkaa ha:lle. Mutasuon koe kylvettiin 4/5, vaaran koe $6 / 5$ 1943. Halla ei lainkaan haitannut viljan kehitystä v. 1943.

Keskimääräinen raakaproteiniprosentti oli viidellä kevätvehnälajikkeella vaaramorenilla 13,76 ja mutaturvesuolla 18,08 (taulukko 2). Raakaproteinin suhteellinen määrä oli jälkimmäisellä $31 \%$ suurempi kuin edellisellä. Tästä huolimatta oli vehnän rouheluku vaaramorenilla säännöllisesti suurempi kuin suolla.

Viljan raakaproteinimäärän vertailevaa tutkimusta jatkettiin koeasemalla v. 1946, jolloin tarkkailtavaksi otettiin 5 kauralajiketta (taulukko 3). Vaaran koe sijoitettiin tänä vuonna karjanlantaa saaneen perunan jälkeen, ja mutasuoviljelykselle annettiin samana vuonna hiekkaa $200 \mathrm{~m}^{3}$ ha:lle. Molemmat kokeet saivat lannoituksena $200 \mathrm{~kg}$ superfosfaattia ja $200 \mathrm{~kg} 50 \%$ kalisuolaa ha:lle. Mutasuoviljelyksen koe kylvettiin $7-8 / 5$, vaaran koe $14-16 / 5$ 1946. Halloja ei esiintynyt viljan kasvuaikana. Heinä-elokuun ankara pouta haittasi erikoisesti vaaralla kasvavan kauran kehitystä, samalla kun se joudutti viljan tuleentumista.

Taulukossa 3 on typpikertoimena raakaproteinimäärää laskettaessa käytetty lukua 5,7. Mainittujen viiden kauralajikkeen keskimääräinen raakaproteini- $\%$ on 
Taulukko 3. Kauralajikkeitten sadot ja sadon laatu vaaramoreenilla ja mutaturvesuolla v. 1946.

Tabelle 3. Erträge und Ertragsbeschaffenheit von Haferzuchtsorten auf Vaara-Moräne und Niederungsmoor im J. 1946.

\begin{tabular}{|c|c|c|c|c|c|c|c|c|}
\hline \multirow[b]{3}{*}{$\begin{array}{c}\text { Lajike } \\
\text { Zuchtsorte }\end{array}$} & \multicolumn{4}{|c|}{ Vaaramoreenilla - Vaara-Moräne } & \multicolumn{4}{|c|}{ Mutaturvesuolla - Niederungsfmoor } \\
\hline & \multicolumn{2}{|c|}{$\begin{array}{l}\text { Sato } \mathrm{kg} / \mathrm{ha} \\
\text { Evtrag }\end{array}$} & \multicolumn{2}{|c|}{$\begin{array}{l}\text { Jyväsadon } \\
\text { Kornertrag }\end{array}$} & \multicolumn{2}{|c|}{$\begin{array}{c}\text { Sato } \mathrm{kg} / \mathrm{ha} \\
\text { Evtrag }\end{array}$} & \multicolumn{2}{|c|}{$\begin{array}{l}\text { Jyväsadon } \\
\text { Kornertrag }\end{array}$} \\
\hline & $\begin{array}{l}\text { jyviä } \\
\text { Körner }\end{array}$ & $\begin{array}{l}\text { olkia } \\
\text { Stroh }\end{array}$ & $\begin{array}{l}\text { kuiva- } \\
\text { aine- } \% \\
\text { Trocken- } \\
\text { substanz- } \\
\% \\
\%\end{array}$ & $\begin{array}{l}\text { raaka- } \\
\text { prot-\% } \\
\text { Rohpro- } \\
\text { tein-\% }\end{array}$ & $\begin{array}{l}\text { jyviä } \\
\text { Körner }\end{array}$ & $\begin{array}{l}\text { olkia } \\
\text { Stroh }\end{array}$ & $\begin{array}{c}\text { kuiva- } \\
\text { aine- } \% \\
\text { Trocken- } \\
\text { substanz- } \\
\% \\
\end{array}$ & $\begin{array}{l}\text { raaka- } \\
\text { prot-\% } \\
\text { Rohpro- } \\
\text { tein-\% }\end{array}$ \\
\hline Kultasade II- & & & & & & & & \\
\hline Guldregn II.. & $1680 \pm 70$ & 3470 & 84,12 & 7,24 & $4690 \pm 230$ & 5420 & 84,70 & 13,11 \\
\hline Esa $\ldots \ldots \ldots$ & $1730 \pm 120$ & 3290 & 84,00 & 7,59 & $5760 \pm 120$ & 5520 & 86,86 & 12,37 \\
\hline Eho .... . & $2510 \pm 190$ & 4110 & 83,16 & 7,41 & $4480 \pm 180$ & 5720 & 87,60 & 12,71 \\
\hline Kytö $\ldots \ldots$ & $1870 \pm 100$ & 2940 & 86,74 & 8,78 & $4680 \pm 180$ & 6020 & 87,42 & 11,63 \\
\hline Orion II ... & $1940 \pm 120$ & 3150 & 86,28 & 7,81 & $4520 \pm 190$ & 5610 & 89,58 & 13,97 \\
\hline
\end{tabular}

ollut vaaramorenilla 7,77 ja mutasuolla 12,76 . Raakaproteinin suhteellinen määrä suokaurassa on siten ollut $64,3 \%$ suurempi kuin vastaavilla vaaramorenilla kasvaneilla lajikkeilla. Näin jyrkkä eroitus on todennäköisesti osaksi johtunut kuivuudesta, joka ahdisti vaaramaalla kasvanutta kauraa, kuten edellä on mainittu.

Vuoden 1947 sadosta jatkettiin koeasemalla proteinianalyysejä. Tutkimus ulotettiin nyt kaikkiin tärkeimpiin toukoviljoihin: kevätvehnään, ohraan ja kauraan. Viimeksimainitusta tutkittiin myös kaksi sellaista näytettä, jotka olivat kasvaneet rahkasuoviljelyksellä. Kemiallinen työ suoritettiin valtion maanviljelyskemiallisessa laboratoriossa Helsingissä. Raakaproteinin lisäksi määritettiin tällä kertaa myös puhdasproteini typpikertoimen ollessa molemmilla 5,7.

Vuonna 1947 hiekoitettiin mutasuon lajikekoeala käyttäen $200 \mathrm{~m}^{3}$ maanparannusainetta ha:lle. Lannoitusta annettiin tälle ja vaaramaan koealalle $200 \mathrm{~kg}$ superfosfaattia $+200 \mathrm{~kg} 40 \%$ kalisuolaa ha:lle. Rahkasuoviljelyksen lajikekokeelle annettiin $250 \mathrm{~kg}$ superf. $+250 \mathrm{~kg} 40 \%$ kalis. $+100 \mathrm{~kg}$ kalkkisalpietaria ha:lle. Ala oli hiekoitettu edellisinä vuosina. Kauralajikkeet kylvettiin mutasuolle $7 / 5$, rahkasuolle $9 / 5$ ja vaaralle $12 / 5$, kevätvehnälajikkeet mutasuolle $8 / 5$ ja vaaralle $13-14 / 5$ sekä ohralajikkeet kummallekin maalajille $17-19 / 5$.

Kasvukausi 1947 oli säittensä puolesta aikaisemmin kuvatuita oikukkaampi. Kesäkuulla haittasi kasvullisuutta pouta ja elokuulla esiintyi ankaroita halloja minimimittarin osoittaessa mutasuoviljelyksen pinnalla tämän kuukauden 19-21 päivien aamuina $-6,9,-9,5$ ja $-7,5$ astetta $C$. Taulukossa 4 mainittavista lajikkeista olivat vain Vega-ohra ja Orion II-kaura ehtineet tätä ennen täysin kypsyä Esa-kauran ollessa hallan tullen juuri tuleentumisen vaiheella. Toisten kevätviljojen suolla kasvanutta jyväsatoa vahingoitti kylmä huomattavasti. Vaaralle eivät nämä elokuun hallat nousseet.

Taulukoiden 4 ja 5 tuloksia tarkastettaessa havaitaan, että alhaisin proteiniprosentti on ollut rahkasuoviljelyksellä kasvaneella kauralla. Ilmeisesti on tämä 
Taulukko 4. Kevätviljalajikkeitten sadot ja sadon laatu vaaramaalla ja mutasuolla v. 1947.

Tabelle 4. Evträge und Ertragsbeschaffenheit von Sommergetreide-Zuchtsorten auf Vaara-Boden und Niederungsmoor im J. 1947 .

\begin{tabular}{|c|c|c|c|c|c|c|c|c|c|c|}
\hline \multirow{3}{*}{$\begin{array}{c}\text { Lajike } \\
\text { Zuchtsorte }\end{array}$} & \multicolumn{5}{|c|}{ Vaaramaalla - Vaara-Boden } & \multicolumn{5}{|c|}{ Mutasuolla - Niederungsmoor } \\
\hline & \multicolumn{2}{|c|}{$\begin{array}{l}\text { Sato } \mathrm{kg} / \mathrm{ha} \\
\text { Evtrag }\end{array}$} & \multicolumn{3}{|c|}{$\begin{array}{l}\text { Jyväsadossa \% } \\
\text { Vom Kornertrag \% }\end{array}$} & \multicolumn{2}{|c|}{$\begin{array}{l}\text { Sato } \mathrm{kg} / \mathrm{ha} \\
\text { Evtrag }\end{array}$} & \multicolumn{3}{|c|}{$\begin{array}{l}\text { Jyväsadossa \% } \\
\text { Vom Kornertrag \% }\end{array}$} \\
\hline & 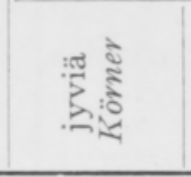 & $\begin{array}{l}\frac{3}{0} \\
\frac{3}{0}\end{array}$ & 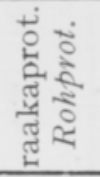 & 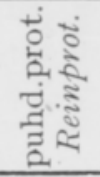 & 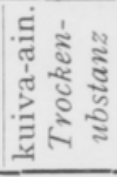 & 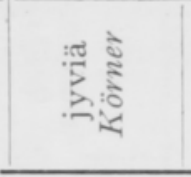 & $\begin{array}{l}\frac{\pi}{3} \\
\frac{5}{0}\end{array}$ & 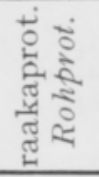 & 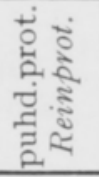 & 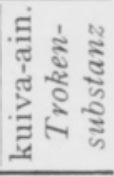 \\
\hline Timantti-vehnä & & & & & & & & & & \\
\hline $\begin{array}{l}\text { Diamant-Weizen } \\
\text { Hopea-vehnä - }\end{array}$ & $1980 \pm 200$ & 3480 & 12,8 & 11,7 & 90,7 & $3000 \pm 110$ & 6100 & 12,2 & 11,0 & 90,9 \\
\hline Weizen ......... & $1400 \pm 180$ & 3380 & 11,6 & 10,5 & 90,8 & $3100 \pm 160$ & 4960 & 11,2 & 10,1 & 90,7 \\
\hline $\begin{array}{l}\text { Binder-ohra - } \\
\text { Gerste } \quad \ldots \ldots \ldots .\end{array}$ & & 4060 & 10,0 & 9,1 & 90,5 & & 5090 & 12,0 & 11,1 & 90,3 \\
\hline Maija-ohra-Gerste & $1060 \pm 120$ & 4090 & 9,5 & 8,7 & 90,5 & $2450 \pm 90$ & 5300 & 11,2 & 10,4 & 90,4 \\
\hline Vega-ohra - Gerste & $830 \pm 100$ & 3320 & 11,3 & 10,6 & 90,6 & $3170 \pm 130$ & 4680 & 13,3 & 12,0 & 90,1 \\
\hline $\begin{array}{l}\text { Kultasade II-kaura } \\
- \text { Guldregn } I I-\end{array}$ & 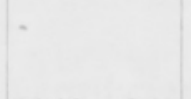 & & & & & & & & & \\
\hline Hafer.......... & $1940 \pm 250$ & 2860 & 10,3 & 9,4 & 91,9 & $3890 \pm 180$ & 5710 & 12,3 & 11,0 & 92,6 \\
\hline Esa-kaura-Hafer & $2010 \pm 220$ & 3160 & 10,1 & 9,5 & 91,1 & $4020 \pm 240$ & 5940 & 12,3 & 11,2 & 94,1 \\
\hline Eho-kaura - Hafer & $1640 \pm 200$ & 3000 & 10,2 & 9,1 & 90,5 & $4430 \pm 130$ & 5430 & 12,3 & 10,9 & 90,1 \\
\hline 0395-kaura-Hafer & $2020 \pm 280$ & 3370 & 9,2 & 8,1 & 91,0 & $4550 \pm 150$ & 5750 & 11,2 & 10,1 & 89,9 \\
\hline $\begin{array}{l}\text { Orion II-kaura }- \\
\text { Hafer ........ }\end{array}$ & $1270 \pm 220$ & 2570 & 11,1 & 10,1 & 90,8 & $3210 \pm 70$ & 4940 & 13,2 & 12,2 & 90,7 \\
\hline
\end{tabular}

johtunut rahkaturpeen typpiköyhyydestä. Taulukossa 4 mainitut kaksi vehnälajiketta ovat tässä tapauksessa koonneet itseensä vaaramaalla suhteellisesti enimmän typellisiä aineita. Eroitus ei kuitenkaan ole ollut kovin suuri mutasuon vehnään verrattuna. Poikkeus on nähtävästi johtunut hallasta, joka katkaisi suolla kasvavan viljan kehityksen kesken.

Edelläesitetyn lisäksi laskettiin keskimääräiset proteiniprosentit viljan kuivaaineesta. Tulokset on esitetty taulukossa 6. Ohran ja kauran proteiniprosentit mutasuoviljelyksellä ovat olleet noin viidenneksen korkeammat kuin vaaramaalla. Suhde on ollut sama raaka- ja puhdasproteinilla.

Taulukko 5. Kauralajikkeitten sadot ja sadon laatu rahkasuoviljelyksellä v. 1947.

Tabelle 5. Evträge und Ertragsbeschaffenheit von Haferzuchtsorten auf Hochmoor-Kultur im J. 1947.

\begin{tabular}{|c|c|c|c|c|c|c|}
\hline & \multirow{2}{*}{$\begin{array}{c}\text { Lajike } \\
\text { Zuchtsorte }\end{array}$} & \multicolumn{2}{|c|}{$\begin{array}{c}\text { Sato } \mathrm{kg} / \mathrm{ha} \\
\text { Evtrag }\end{array}$} & \multicolumn{3}{|c|}{$\begin{array}{c}\text { Jyväsadossa \% } \\
\text { Vom Kornertrag \% }\end{array}$} \\
\hline & & $\begin{array}{l}\text { jyviä } \\
\text { Körner }\end{array}$ & $\begin{array}{l}\text { olkia } \\
\text { Stroh }\end{array}$ & $\begin{array}{c}\text { raakaprot. } \\
\text { Rohprot. }\end{array}$ & $\begin{array}{c}\text { puhdasprot. } \\
\text { Reinprot. }\end{array}$ & $\begin{array}{c}\text { kuiva-ain. } \\
\text { Trocken- } \\
\text { substanz }\end{array}$ \\
\hline Kultasade II & $\ldots \ldots \ldots \ldots \ldots \ldots \ldots$ & $1640 \pm 60$ & 2500 & 9,6 & 8,6 & 92,5 \\
\hline Esa ....... & $\ldots \ldots \ldots \ldots \ldots \ldots$ & $1510 \pm 50$ & 2200 & 9,6 & 7,9 & 90,9 \\
\hline
\end{tabular}


Taulukko 6. Raaka- ja puhdasproteinimäärien keskiarvot eri maalajeilla viljan kuiva-aineessa v. 1947. Tabelle 6. Die Mittelwerte der Roh- und Reinproteinmengen aus Trockensubstanz des Getreides auf verschiedenen Bodenarten im J. 1947.

\begin{tabular}{|c|c|c|c|c|c|c|c|c|c|c|c|c|}
\hline \multirow{3}{*}{$\begin{array}{c}\text { Viljalaji } \\
\text { Getreideart }\end{array}$} & \multicolumn{4}{|c|}{$\begin{array}{l}\text { Vaaramaalla } \\
\text { Vaara-Boden }\end{array}$} & \multicolumn{4}{|c|}{$\begin{array}{c}\text { Mutasuolla } \\
\text { Niederungsmoor }\end{array}$} & \multicolumn{4}{|c|}{$\begin{array}{c}\text { Rahkasuolla } \\
\text { Hochmoor }\end{array}$} \\
\hline & \multicolumn{2}{|c|}{ 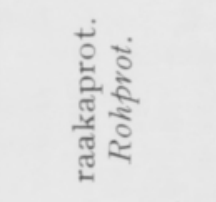 } & \multicolumn{2}{|c|}{ 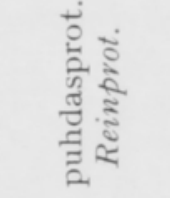 } & \multicolumn{2}{|c|}{ 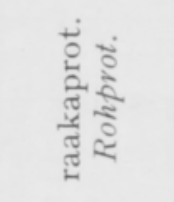 } & \multicolumn{2}{|c|}{ 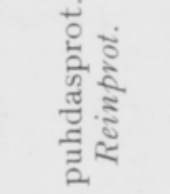 } & \multicolumn{2}{|c|}{ 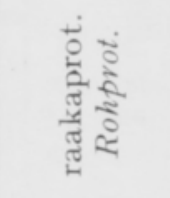 } & \multicolumn{2}{|c|}{ 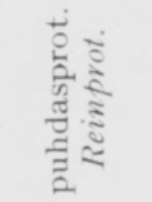 } \\
\hline & $\%$ & \begin{tabular}{|c|} 
suhde- \\
luku \\
Ver- \\
hältnis- \\
zahl
\end{tabular} & $\%$ & $\begin{array}{l}\text { s.l. } \\
V . z .\end{array}$ & $\%$ & $\begin{array}{l}\text { s.l. } \\
\text { V.z. }\end{array}$ & $\%$ & $\begin{array}{l}\text { s.l. } \\
\text { V.z. }\end{array}$ & $\%$ & $\begin{array}{l}\text { s.l. } \\
\text { V.z. }\end{array}$ & $\%$ & $\begin{array}{l}\text { s.l. } \\
\text { V.z. }\end{array}$ \\
\hline Kevätvehnä - Sommerweizen & 13,4 & 100 & 12,2 & 100 & 12,9 & 96 & 11,6 & 95 & & & & \\
\hline Ohra - Gerste ........... & 11,3 & 100 & 10,4 & 100 & 13,5 & 119 & 12,4 & 119 & & & & \\
\hline Kaura - Hafer.......... & 11,2 & 100 & 10,1 & 100 & 13,4 & 120 & 12,1 & 120 & 10,5 & 94 & 9,0 & 87 \\
\hline
\end{tabular}

Edelleen olisi kiintoisaa tarkastaa, mitä valkuaisaineryhmää mutasuolla kasvaneessa viljassa on runsaimmin muodostunut. Tällaisiin tutkimuksiin ei koeasemalla kuitenkaan ole tilaisuutta. Mitään karjan ruokinnassa tehottomia valkuaisryhmään kuuluvia aineita eivät suolla kasvaneen viljan proteinit voine olla. Tähän suuntaan viittaa, että raakaproteinin ja puhdasproteinin suhde on sekä vaaralla että suolla kasvaneessa viljassa pysynyt jokseenkin samana.

\section{$\mathrm{P}$ ä ät e $1 \mathrm{~m}$ ät.}

Tutkimuksen tuloksena mainittakoon seuraavaa:

Mutasuoviljelyksillä on maakerroksessa, jota kasvien juuret käyttävät hyväkseen, turpeeseen sidottua typpeä 3-4-kertainen määrä kivennäismaihin verrattuna .

Edellisestä johtuen kokoavat kevätvehnä, ohra ja kaura mutasuoturpeella kasvaessaan itseensä huomattavasti enemmän typellisiä aineita kuin kivennäismaalla. Selostetuissa tapauksissa on tämä proteiniaineiden suhteellisen määrän eroitus viljan jyvissä vaihdellut 19:stä 64:ään prosenttiin.

Raaka- ja puhdasproteinin suhde on pysynyt jokseenkin samana kivennäismaalla ja mutasuolla kasvaneessa viljassa.

Poikkeuksen päinvastaiseen suuntaan edelläesitettyyn nähden teki kevätvehnä v. 1947. Silloin vehnä paleltui suoviljelyksellä ennen tuleentumista, jota vastoin se kivennäismaalla ehti kypsyä ennen hallan tuloa. 


\section{KIRJALLISUUSLUETTELO.}

(1) Kivinen, E. 1949. Suotiede. Porvoo-Helsinki.

(2) Rindell, A. 1904. Onko suoviljelykseltä saatu sato laadultaan huonompaa kuin kiinteän maan sato. Suoviljelysyhdistyksen Vuosikirja 1904, p. 25-33. Helsinki.

(3) VAlle, O. 1946. Palkokasvien merkitys rehuviljan tuotannossa. Maatalous ja Koetoiminta I, p. $115-134$.

(4) Valmari, J. ja Salonen, M. 1940. Lannoitusoppi. Porvoo-Helsinki.

(5) Vuosikertomus Maatalouskoelaitoksen maatutkimusosaston toiminnasta v. 1935, p. 10-13. Helsinki.

REFERAT.

ÜBER DAS SCHWANKEN DER PROTEINSTOFFE BEI DEM AUF VAARA-MORÄNE UND NIEDERUNGSMOOR GEWACHSENEM GETREIDE.

LaUri Saloheimo.

Karelische Moorkultur-Versuchsstation, Tohmajärvi.

Bei den Niederungsmoorkulturen Finnlands enthält die Bodenschicht, die die Wurzeln der Pflanzen sich zunutze machen, 3-4mal soviel Stickstoff, an den Torf gebunden, wie die Festböden (4). In der Untersuchung wird, gegründet auf Versuche, die an der karelischen Moorkultur-Versuchsstation ausgeführt worden sind, die Nahrungsaufnahme der Pflanzen erörtert. Es handelt sich um auf VaaraMoräne und auf Niederungsmoor gewachsenen Sommerweizen, Hafer und Gerste, über deren Erträge in den Jahren 1943, 1946 und 1947 Stickstoffbestimmungen gemacht worden sind, sowie um einen 1947 angestellten Versuch mit Hafer auf Hochmoorkultur. Die Ergebnisse erweisen (Tab. 2, 3 und 4), dass die angeführten Pflanzen, wenn sie auf stickstoffreichen Modertorfstandboden wachsen, verhältnismässig mehr stickstoffhaltige Stoffe als auf Vaara-Moräne in sich ansammeln. In den untersuchten Fällen hat dieser Unterschied in der relativen Menge der Proteinstoffe in den Getreidekörnern zwischen 19 und 64 Prozent gewechselt. Das Verhältnis zwischen Roh- und Reinprotein ist auf beiden bodenarten dasselbe geblieben (Tab. 6), so dass die stickstoffhaltigen Stoffe in beiden Fällen gleichwertig zu sein scheinen. Eine Ausnahme gegenüber den übrigen Versuchen machte der Sommerweizen in dem Versuchsjahr 1947 (Tab. 4). Damals unterbrach der Nachtfrost das Reifen des auf Niederungsmoor gewachsenen Weizen, wodurch dieser etwas weniger stickstoffreiche Stoffe enthielt als der auf VaaraMoräne gewachsene Weizen. 